\title{
Amygdalar Lesions Block Discriminative Avoidance Learning and Cingulothalamic Training-Induced Neuronal Plasticity in Rabbits
}

\author{
Amy Poremba ${ }^{1}$ and Michael Gabriel ${ }^{2}$ \\ ${ }^{1}$ Department of Psychology and Institute for Neuroscience, University of Texas, Austin, Texas 78712, and ${ }^{2}$ Department of \\ Psychology and Beckman Institute, University of Illinois, Champaign, Illinois 61820
}

Learning to fear dangerous situations requires the participation of neurons of the amygdala. Here it is shown that amygdalar neurons are also involved in learning to avoid dangerous situations. Amygdalar lesions severely impaired the acquisition of acoustically cued, discriminative instrumental avoidance behavior of rabbits. In addition, the development of anterior cingulate cortical and medial dorsal thalamic training-induced neuronal plasticity in the early stages of behavioral acquisition was blocked in rabbits with lesions. The development of training-induced neuronal plasticity in the medial dorsal and anterior thalamic nuclei in late stages of behavioral acquisition was also blocked in rabbits with lesions. These results indicate that the integrity of the amygdala is essential for the establishment of both early and late training-induced cingulothalamic neuronal plasticity. It is hypothesized that amygdalar traininginduced neuronal plasticity in the initial trials of conditioning represents a substrate of learned fear, essential for the early and late cingulothalamic plasticity that is involved in mediation of acquisition of the instrumental avoidance response.

Key words: limbic thalamus; cingulate cortex; amygdala; learning; operant conditioning; anterior ventral nucleus; medial dorsal nucleus
Much information concerning the neural mediation of learned behavior has been provided by studies using the "model system" approach. These studies focus effort on the analysis of a single learning paradigm in a particular species (Carew et al., 1984; Steinmetz and Thompson, 1991; Gabriel, 1993). The present study continues an analysis of discriminative avoidance, wherein rabbits learn to step in an activity wheel in response to a tone that predicts foot shock, and they learn to ignore a different tone that does not predict foot shock.

Past studies using lesions and multisite recording of neuronal activity have demonstrated that the cingulate cortex and the interconnected medial dorsal (MD) and anterior thalamic nuclei are essential for learning, and that neurons in these areas exhibit massive training-induced neuronal plasticity during learning (for review, see Gabriel, 1993). The thalamic training-induced neuronal plasticity does not depend on cerebral cortical afferents, because lesions in projecting cingulate cortical and hippocampal formation areas did not interfere with, indeed they enhanced, the development of the thalamic plasticity (Gabriel et al., 1987, 1991).

Here, we tested the hypothesis that the integrity of the amygdala is essential for the development of training-induced plasticity in the anterior cingulate cortex and MD nucleus. This hypothesis was based on the following results: (1) the traininginduced plasticity of amygdalar, anterior cingulate cortical and MD thalamic neurons develops in parallel, in the early stages of learning; the plasticity in these areas diminishes as asymptotic levels of performance are attained (Applegate et al., 1982; Pascoe and Kapp, 1985; Nishijo et al., 1988; Gabriel, 1990; Maren et al., 1991); (2) amygdalar neurons send axons directly

\footnotetext{
Received Dec. 6, 1996; revised April 14, 1997; accepted April 21, 1997.

This research was supported by National Institutes of Health Grant NS26736 to M.G.

Correspondence should be addressed to Dr. Michael Gabriel, University of Illinois, Beckman Institute, 405 North Mathews, Urbana, IL 61801.

Copyright (C) 1997 Society for Neuroscience $0270-6474 / 97 / 175237-08 \$ 05.00 / 0$
}

to the anterior cingulate cortex and the MD nucleus (Krettek and Price, 1978; Porrino et al., 1981; Price and Amaral, 1981; Price et al., 1987); and (3) the amygdala is involved in mediating acquisition of other aversively motivated behaviors (Blanchard and Blanchard, 1972; Spevack et al., 1975; Gentile et al., 1986; Hitchcock and Davis, 1987; LeDoux et al., 1988; Cahill and McGaugh, 1990; Willner et al., 1991; Helmstetter, 1992; Kapp et al., 1992; Fanselow et al., 1994).

Rabbits received bilateral electrolytic lesions or sham lesions centered in the basolateral nucleus of the amygdala. Fixed position electrodes for chronic recording of multiunit neuronal activity were implanted in the anterior cingulate cortex and the MD nucleus. Recording electrodes were also placed in the anteroventral (AV) thalamic nucleus, because neurons in this area are also involved in the mediation of discriminative avoidance learning. However, because anterior thalamic neurons do not exhibit training-induced plasticity until late stages of behavioral acquisition, the amygdalar lesions were not expected to interfere with plasticity development in this area.

The amygdalar lesions were expected to retard but not to block the acquisition of the discriminative avoidance response, because this was the result obtained previously in rabbits with lesions restricted to the cingulothalamic areas that develop traininginduced plasticity in the early stages of behavioral acquisition (for review, see Gabriel, 1990).

\section{MATERIALS AND METHODS}

Subjects. The subjects were 33 male New Zealand White rabbits weighing $1.5-2.0 \mathrm{~kg}$ on delivery to the laboratory and maintained on ad libitum water and 1 cup of rabbit chow daily. This mild restriction has been found to maintain health and prevent obesity.

Surgical implantation of recording electrodes and lesion administration. After a minimum period of 1 week for adaptation to living cages, each rabbit underwent surgery for implantation of microelectrodes for recording of multiunit neuronal activity. Surgical anesthesia was induced by subcutaneous injection ( $1 \mathrm{ml} / \mathrm{kg}$ body weight) of a solution containing $60 \mathrm{mg} / \mathrm{ml}$ ketamine $\mathrm{HCl}$ and $8 \mathrm{mg} / \mathrm{ml}$ xylazine, followed by hourly 
injections of $1 \mathrm{ml}$ of the solution. The rabbits were placed in a Kopf stereotaxic rabbit head clamp. Six intracranial recording electrodes were lowered through burr holes (diameter, $0.5 \mathrm{~mm}$ ) drilled in the skull over the target sites. The electrodes were made with stainless steel insect pins (number 00; shaft diameter, $0.28-0.30 \mathrm{~mm}$ ) insulated with Epoxylite. The recording surfaces were made by removing insulation from the tip of the pins. The recording surface lengths ranged from 10 to $50 \mu \mathrm{m}$, from tip to insulation, and electrical impedances ranged from $500,000 \Omega$ to $2 \mathrm{M} \Omega$. Miniature Teflon cylindrical electrode guides (length, $2.5 \mathrm{~mm}$; diameter, $1.5 \mathrm{~mm}$ ) impaled on noninsulated pins were positioned over each burr hole and affixed to the skull using dental acrylic. The pins were removed from the guides after the dental acrylic was set. The recording electrodes were slowly advanced to the targets by press fitting them through the holes in the Teflon guides. The Teflon guides held the electrodes firmly during implantation, rendering unnecessary attachment of the electrodes to the stereotaxic manipulator. This greatly reduced the risk that slight movements of the rabbit (e.g., caused by respiration) would damage cells at the electrode tips. Wires were presoldered to the electrodes and to each of six contacts of a nine-contact Amphenol connector, which was also affixed to the skull with dental acrylic and stainless steel machine screws. A stainless steel machine screw threaded into the frontal sinus and connected to one of the Amphenol contacts served as the reference electrode. Neuronal activity was monitored acoustically and with an oscilloscope during electrode advancement to guide electrode placement.

Recording electrodes were implanted into the anterior cingulate cortex (Brodmann's area 24b) and in the AV and MD thalamic nuclei. The stereotaxic coordinates for the recording electrodes were: anteroposterior $(\mathrm{AP}),+2.0 \mathrm{~mm}$; lateral $(\mathrm{L}), \pm 2.3 \mathrm{~mm}$; and ventral $(\mathrm{V}), 7.5 \mathrm{~mm}(\mathrm{AV}$ thalamic nucleus); AP, $+4.6 \mathrm{~mm}$; $\mathrm{L}, \pm 1.5 \mathrm{~mm}$; and $\mathrm{V}, 8.25 \mathrm{~mm}$ (MD thalamic nucleus); and AP, $-4.0 \mathrm{~mm}$; L, $\pm 0.8 \mathrm{~mm}$; and $\mathrm{V}, 3.0 \mathrm{~mm}$ (anterior cingulate cortex) (Girgis and Shih-Chang, 1981).

Seventeen rabbits received bilateral electrolytic lesions of the amygdala, and 16 rabbits received recording electrodes and sham lesions (the lesioning electrodes were lowered, but no current was passed). All lesions except as indicated below were made during the surgery for implantation of the recording electrodes. The lesions were made by passing a $1.5 \mathrm{~mA}$ cathodal DC current for $15 \mathrm{sec}$ through lesioning electrodes identical to the recording electrodes in all respects except the length of the exposed tip (range of tip length, $0.5-0.6 \mathrm{~mm}$ ). The coordinates for the lesions were centered in the basolateral amygdalar nucleus. One, two, or three lesion sites were used as follows: one site, $\mathrm{AP},+0.5 \mathrm{~mm} ; \mathrm{L}= \pm 5.0 \mathrm{~mm}$; and $\mathrm{V}$, $+15.7 \mathrm{~mm}(n=8)$; two sites, AP, $+0.5 \mathrm{~mm} ; \mathrm{L}, \pm 5.0 \mathrm{~mm}$; and $\mathrm{V},+15.7$ $\mathrm{mm}$ and $\mathrm{AP},+0.5 \mathrm{~mm} ; \mathrm{L}, \pm 7.0 \mathrm{~mm}$; and $\mathrm{V},+13.7 \mathrm{~mm}(n=4)$; and three sites, $\mathrm{AP},+1.0 \mathrm{~mm} ; \mathrm{L}= \pm 6.5 \mathrm{~mm}$; and $\mathrm{V},+13.7 \mathrm{~mm}$; $\mathrm{AP},+1.0 \mathrm{~mm}$; $\mathrm{L}$, $\pm 5.0 \mathrm{~mm}$; and $\mathrm{V},+15.3 \mathrm{~mm}$; and $\mathrm{AP},+0.5 \mathrm{~mm} ; \mathrm{L}, \pm 5.0 \mathrm{~mm}$; and $\mathrm{V}$, $+15.7 \mathrm{~mm}(n=5)$. Because the first subject to receive the three-lesion protocol died, the third lesion was made subsequently $7 \mathrm{~d}$ after original surgery, with full anesthesia, through electrodes permanently implanted during the original surgery.

Discriminative avoidance training. Details of the procedures are presented in other reports (e.g., Gabriel, 1993). A minimum of $7 \mathrm{~d}$ intervened between surgery and the onset of behavioral training. Training was not initiated until the rabbits exhibited normal intake of rabbit chow and water. Avoidance training, administered in a rotating wheel conditioning apparatus (Brogden and Culler, 1936), involved the successive presentation in a random order of two $0.5 \mathrm{sec}$ auditory stimuli, a positive conditional stimulus $(\mathrm{CS}+)$ and a negative conditional stimulus (CS-). The stimuli were either pure tones $(1 \mathrm{or} 8 \mathrm{kHz}, 85 \mathrm{~dB}$ re $\left.20 \mathrm{~N} / \mathrm{m}^{2}\right)$ or white noise $\left(75 \mathrm{~dB}\right.$ re $\left.20 \mathrm{~N} / \mathrm{m}^{2}\right)$. Onset of the $\mathrm{CS}+$ was followed after $5 \mathrm{sec}$ by a $1.5 \mathrm{~mA}$ constant current shock delivered to the rabbits' paws through the grid floor of the wheel apparatus. The foot shock was terminated after $0.2-0.4 \mathrm{sec}$ by locomotion-induced wheel rotation. Locomotion after CS + presentation but before the foot shock prevented the scheduled foot shock. The CS- was never followed by foot shock. The assignment of stimuli as CS + and CS - was counterbalanced. The rabbits learned to avoid the foot shock by stepping in response to the $\mathrm{CS}+$, and they learned to ignore the $\mathrm{CS}-$. Thirty-three rabbits were given $120 \mathrm{CS}$ presentations (trials) daily, 60 with the CS+ and 60 with the $\mathrm{CS}-$, until behavioral discrimination reached a criterion, the requirement that locomotory responses be performed more frequently to the CS+ than to the CS-, by at least $60 \%$, in two consecutive training sessions. Each rabbit received two preliminary sessions on 2 consecutive days before the first training session. In the first preliminary training session 120 presentations of the tones to be

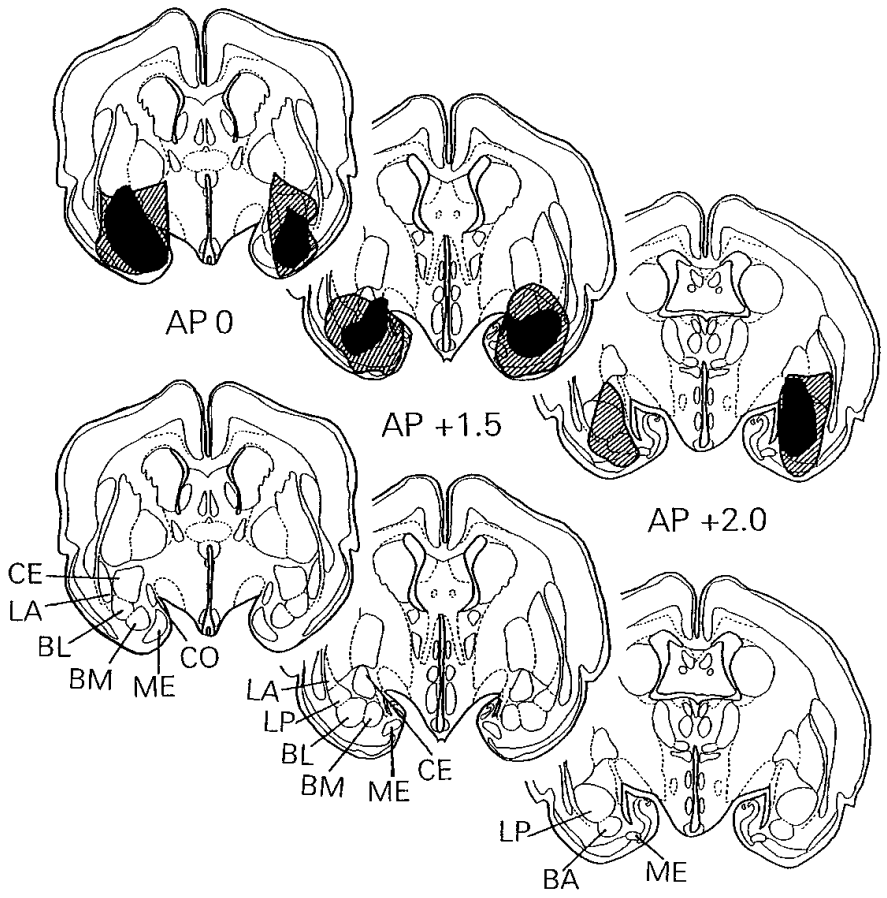

Figure 1. Schematic coronal sections at three AP levels of the rabbit brain: bregma $(A P O), 1.5 \mathrm{~mm}$ posterior to bregma $(A P+1.5)$, and $2.0 \mathrm{~mm}$ posterior to bregma $(A P+2.0)$. The largest and smallest amygdalar lesions are shown, respectively, by the hatched and dark areas. The corresponding schematic sections in the lower part of the figure portray the central $(C E)$, lateral-anterior $(L A)$, basolateral $(B L)$, basomedial $(B M)$, medial $(M E)$, cortical $(C O)$, lateroposterior $(L P)$, and basal accessory $(B A)$ amygdalar areas.

used as CS + and CS - were given without the foot shock. In the second preliminary session 120 tone presentations were accompanied by 30 unpaired foot shock presentations (foot shocks not preceded by any CS). The preliminary sessions provided "baseline" control data for the assessment of later associative, training-induced neuronal and behavioral activity.

Histology. After completion of training, the rabbits were killed with an overdose of sodium pentobarbital. After deep anesthesia was established the rabbits were perfused transcardially with normal saline and $10 \%$ formalin. The brains were removed, frozen, and sectioned at $40 \mu \mathrm{m}$. The sections were photographed while still wet. After drying the sections were stained with formol-thionin.

For lesion quantification, the number of $0.25 \mathrm{~mm}$ grid squares covering the damaged portion of the amygdalar nuclei was counted bilaterally in each of four coronal sections spaced $1 \mathrm{~mm}$ apart from $0.5 \mathrm{~mm}$ anterior to bregma to $2.5 \mathrm{~mm}$ posterior to bregma. The average percentage of damaged relative to spared amygdalar tissue over sections and hemispheres was calculated for each rabbit. Eight rabbits with scores of $>15 \%$ were designated as having lesions. The average score for this group of rabbits was $33.5 \%$ (range, 15-57\%). Because the lesions were centered in the basolateral nucleus, this area was damaged consistently in all rabbits with lesions. The largest and smallest lesions in the eight rabbits with damage scores of $>15 \%$ are depicted in Figure 1.

Scores were also calculated for the percentage of damaged relative to spared amygdalar tissue, bilaterally, for eight separate areas of the amygdala. The average damage scores for the eight rabbits with lesions were: basolateral nucleus, $55.25 \%$; central nucleus, $53.13 \%$; lateral nucleus, 22.63\%; basomedial nucleus, $60.88 \%$; anterior medial nucleus, $9.25 \%$; cortical amygdalar nucleus, $16.25 \%$; and cortico-amygdalar transitional zone, $32.75 \%$. Minor damage found in nearby areas was distributed as follows: interstitial nucleus of the stria terminalis, $4.12 \%$; putamen, $2.45 \%$; and piriform cortex, $2.13 \%$.

Thirty-one of the electrodes from the lesion and sham lesion groups yielded viable neuronal recordings and were located in the target sites, respectively, as follows: 10 and 19 in anterior cingulate cortex, eight and eight in the AV nucleus, and eight and seven in the MD nucleus. 
Recording and analysis of neuronal activity. Throughout behavioral training the neuronal activity was fed into active bandpass filters (bandwidth, 600-8000 Hz) and subsequently to pulse height discriminators, set to detect the largest three or four neuronal spikes present on the record. Outputs of the discriminators were fed to a computer, programmed to control task administration and to sample the neuronal data before and during CS presentation. The computer sampled the average frequency of multiunit firing in each of 100 consecutive 10 msec intervals, 30 before and 70 after CS onset. The frequencies in the intervals after CS onset were normalized with respect to the frequencies in the 30 consecutive $10-\mathrm{msec}$ pre-CS (baseline) intervals, using the $z$ transformation. This normalization procedure provides a standard quantification of the CS-elicited neuronal discharge, permitting direct comparison of discharge magnitudes between recordings in different areas and subjects.

The multiunit recording technique used here combines the firing frequencies of several cells. With this approach it is possible to obtain a robust measure of localized learning-relevant neuronal activity, which remains stable over many days. Whereas the multiunit activity cannot document all relevant neuronal firing patterns, it has been shown to provide a reliable representation of the modal pattern of single-unit firing in these areas (Kubota et al., 1996).

A central feature of this and related studies is the use of discriminative neuronal activity to assay learning-relevant brain processes. Discriminative neuronal activity is defined as significantly different neuronal firing in response to signals that have different learned meanings, the $\mathrm{CS}+$ that predicts the aversive reinforcer, and the $\mathrm{CS}-$ that predicts that no aversive reinforcer will occur. Discriminative activity has the advantage that it is unambiguously associative in character; i.e., it cannot be attributed to nonassociative factors such as arousal, motor preparation, and pseudo-conditioning.

The neuronal and behavioral data were submitted to multifactor factorial repeated measures ANOVA (BMDP statistical software program $2 \mathrm{~V})$. Factors of the analysis yielding significant overall $F$ ratios were further analyzed using simple effect tests following procedures outlined by Winer (1962). Correction of the $F$ test attributable to disconformity of the data with the sphericity assumption of these analyses was performed following the procedure of Huynh and Feldt (1976).

\section{RESULTS}

\section{Behavior}

Behavioral learning was severely impaired in rabbits with lesions. Five of the eight rabbits with lesions and one of 16 rabbits with sham lesions failed to attain the criterion of acquisition. For these rabbits a value of 15 was assigned, the maximum number of training sessions administered before declaring failure to learn.

Analysis of the number of sessions required for criterion attainment, including the aforementioned scores of 15 , showed that rabbits with lesions required significantly more training sessions (mean, 13.00) to attain the criterion than did the rabbits with sham lesions [mean, 5.43; $F_{(1,22)}=28.44 ; p<0.0001$ ]. Two of the three rabbits with lesions that learned were nevertheless severely impaired, requiring 12 and 13 training sessions, respectively, to reach the criterion of acquisition. The remaining rabbit with a lesion completed the criterion in five sessions.

Analysis of the percentage of conditioned avoidance responses was computed with factors of group (lesion and sham lesion), stimulus ( $\mathrm{CS}+$ and $\mathrm{CS}-$ ), and training stage (the preliminary training session with unpaired CS and foot shock presentations, the first session of conditioning, the session of first significant behavioral discrimination, and the session in which the criterion of learning was attained). The session of the first significant discrimination was the first session, for a given rabbit, in which the locomotory response was performed on $25 \%$ more of the CS+ trials than on CS - trials. Data analyzed for rabbits that did not reach the first significant discrimination were obtained from the second training session, which corresponded to the average session in which successful rabbits reached the first significant be-

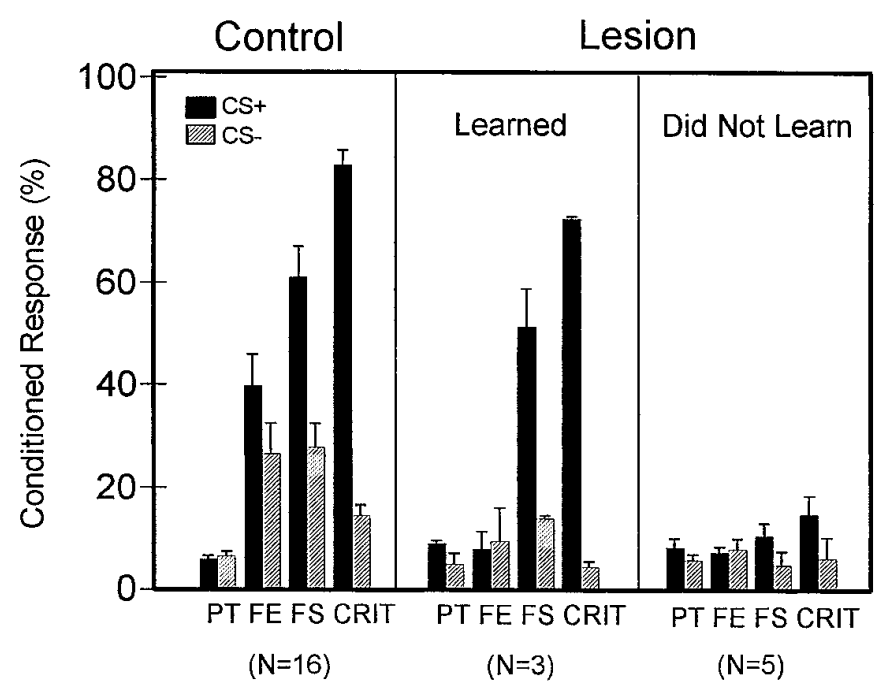

Figure 2. Percentage of conditioned responses performed in response to the CS + during each daily training session (day) for controls $(n=15)$, lesioned rabbits that learned $(n=3)$, and lesioned rabbits that did not learn $(n=5)$. Training was terminated for the lesioned rabbits that did not reach significant behavioral discrimination (see text) by the seventh training day. The plotted scores for the control group exclude data of one rabbit that did not learn.

havioral discrimination. Data analyzed for rabbits that did not reach the criterion were obtained from their final training session.

A severe deficit of avoidance response performance occurred in all training stages in the rabbits with lesions. This was indicated by simple effect tests after a significant interaction of the group, training stage, and stimulus factors $\left[F_{(3,66)}=8.71 ; p<0.001\right]$. The percentages of conditioned responses performed to the CS+ were $9.63,21.25$, and $29.25 \%$ during the first conditioning session, the session of the first significant discrimination, and the session of criterion attainment, respectively, whereas the corresponding percentages in controls in the same sessions were, respectively, 39.75, 61.12 , and $82.94 \%$. The difference at each training stage was significant $(p<0.01)$.

The rabbits with lesions that did not reach the criterion $(n=5)$ did not perform conditioned responses more frequently than during preliminary training, and the rabbits with lesions that attained the criterion $(n=3)$ exhibited significantly reduced rates of avoidance relative to the controls during the early training sessions (Fig. 2).

Correlational analyses indicated a clear relationship between the amount of lesion-related damage in specific amygdalar nuclei and behavioral performance in the rabbits with lesions. Average scores indicating damage in all amygdalar areas were not predictive of behavioral performance $(r=-0.03)$; however, a significant negative correlation was found for the percentage of conditioned responses performed at the criterion and the damage scores for two of the areas, the central nucleus $(r=-0.84 ; p<0.01)$ and the lateral nucleus $(r=-0.70 ; p<0.05)$. The rabbits with lesions that reached the criterion had the smallest damage scores in these areas (Fig. 3). Damage scores for the basolateral nucleus also predicted behavioral performance $(r=-0.33)$, although this correlation was not significant.

\section{Training-induced neuronal plasticity}

This plasticity was defined as significant discriminative neuronal activity, i.e., a significantly different neuronal discharge in response to the $\mathrm{CS}+$, compared with the discharge elicited by the 
Amygdaloid Nuclei

Central

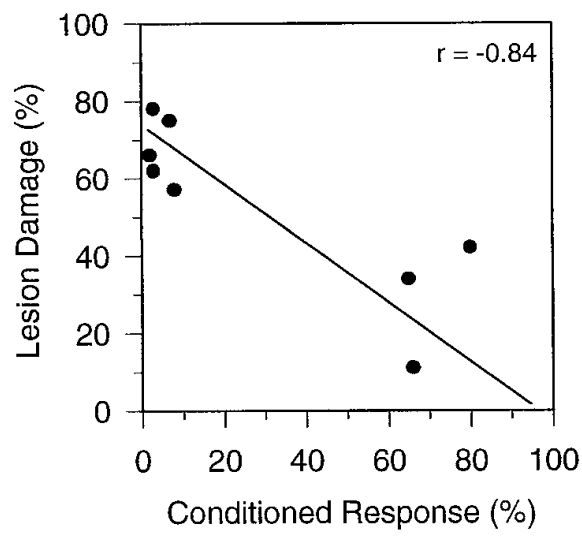

Lateral

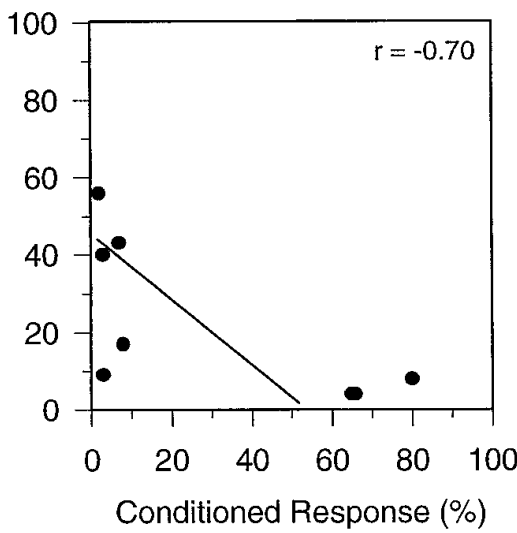

Basolateral

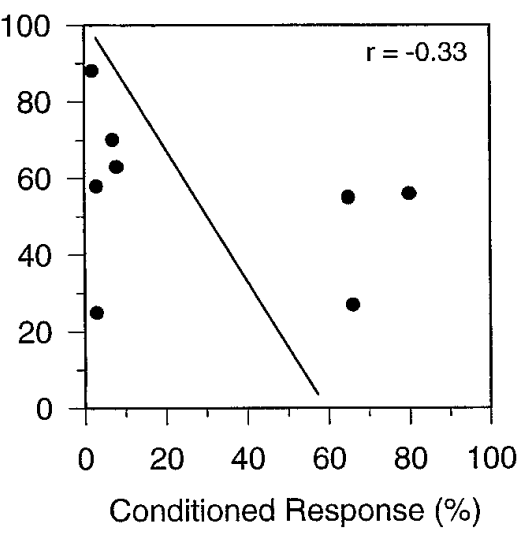

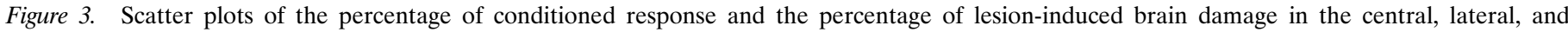

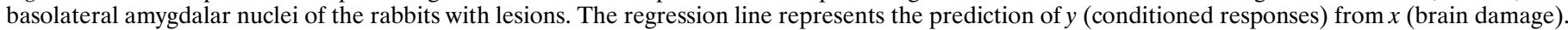

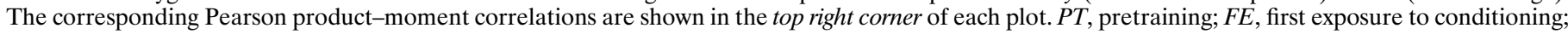
$F S$, first significant discrimination; CRIT, criterion attainment.
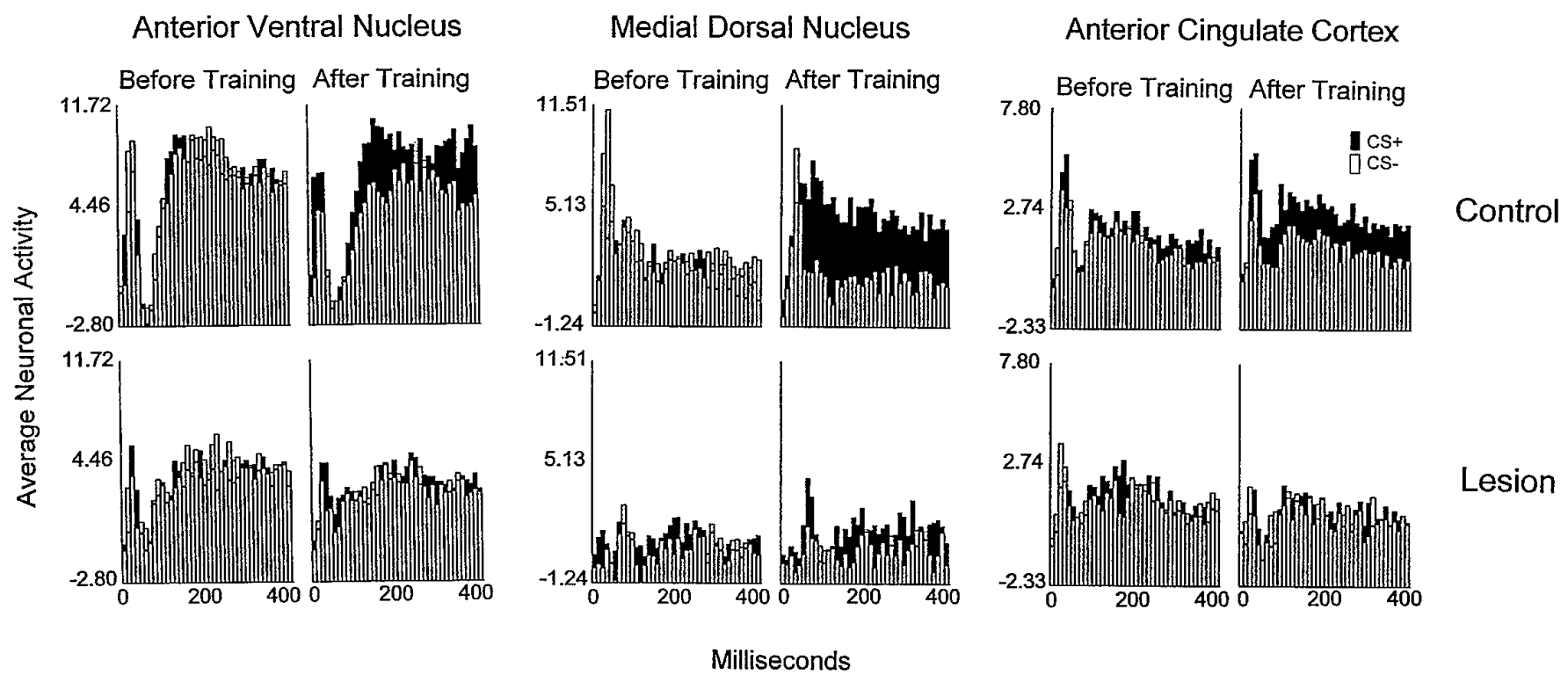

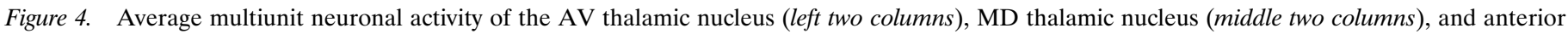

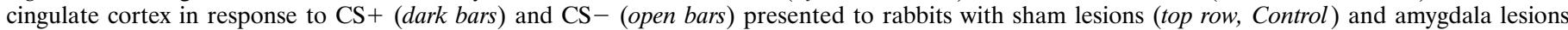

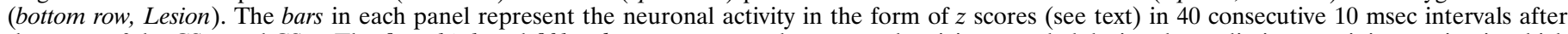

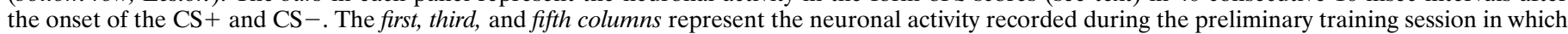

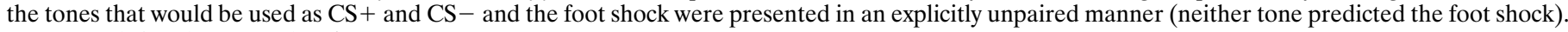

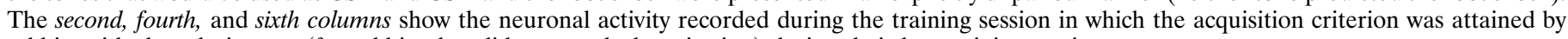
rabbits with sham lesions or (for rabbits that did not reach the criterion) during their last training session.

CS - (see Materials and Methods). Multifactor factorial repeated measures ANOVA was computed on the average neuronal firing frequency ( $z$ scores, see Materials and Methods) in four consecutive 100-msec intervals after onset of the CS + and CS - . Significant training-induced discriminative neuronal activity developed as expected in all monitored areas in rabbits with sham lesions. However, discriminative activity did not develop in the rabbits with lesions (Fig. 4). This conclusion was based on significant interactions of the group, training stage, and stimulus factors [anterior cingulate cortex, $F_{(3,87)}=4.02 ; p<0.02$; AV nucleus,
$F_{(3,42)}=3.12 ; p<0.04$; and MD nucleus, $\left.F_{(3,39)}=3.19 ; p<0.04\right]$. Simple effect tests indicated the occurrence of significant traininginduced neuronal discrimination between the CS+ and the CSin the controls. The average neuronal discharge frequency elicited by the CS + exceeded significantly the discharge frequency elicited by the CS- during the first session of conditioning (anterior cingulate cortex, $p<0.05$ ), the session of first significant behavioral discrimination (MD nucleus, $p<0.05$; anterior cingulate cortex, $p<0.01$ ), and during the session in which the criterion of behavioral acquisition was attained (anterior cingulate cortex, $p<$ 
0.01; AV nucleus, $p<0.05$; MD nucleus, $p<0.01)$. No significant discriminative activity occurred in these areas during the preliminary training session with tones and unpaired foot shock presentations.

\section{Latencies of the discriminative neuronal plasticity}

Significant discriminative neuronal activity during the session in which the criterion was attained first occurred in the third $10-\mathrm{msec}$ interval (20-30 msec after tone onset) in the anterior cingulate cortex, the sixth interval $(50-60 \mathrm{msec})$ in the MD nucleus, and the 12th interval (110-120 msec) in the AV nucleus. Significant discrimination was first exhibited at the seventh interval (60-70 msec after CS onset) in the basolateral nucleus of the amygdala in trained rabbits (Maren et al., 1991). Significant discriminative activity occurred in the majority of later intervals after tone onset in all three areas. This information may indicate the sequence in which areas of the learning-relevant circuit are associatively activated during conditioning trials: anterior cingulate cortex $>$ MD nucleus $>$ basolateral amygdala $>$ AV thalamic nucleus. The brief interval from CS onset to significant neuronal discrimination in all areas rules out the possibility that the discriminative neuronal activity could have been a byproduct of the rabbits' discriminative behavioral response, which did not occur until 2.5 or more sec after tone onset.

\section{Neuronal activity in rabbits that learned and did not learn}

Analyses were carried out to compare the neuronal activity of the rabbits with lesions that reached the criterion of learning $(n=3)$ with the activity of rabbits that did not reach the criterion $(n=5$, see Results, Behavior). It was expected that cingulothalamic neuronal plasticity would be found in the rabbits that learned but not in those that failed to learn. Although the numbers of neuronal records available for these analyses were very small, the results were as expected. Analyses of the spike frequency data of the MD nucleus yielded an interaction of the group (learned or did not learn), training stage, and stimulus factors $\left[F_{(3,24)}=3.35 ; p<\right.$ 0.039]. Simple effect tests demonstrated significant discriminative plasticity (greater spike frequency in response to the $\mathrm{CS}+$ than to the $\mathrm{CS}-$ ) during the sessions of first significant behavioral discrimination and criterion attainment $(P<0.05$ in each case). However, no significant discrimination occurred in rabbits that did not learn. Simple effect tests yielded the same results for data of the anterior cingulate cortex after an analysis that yielded an interaction that approached significance $(P<0.080)$. Analysis of the data of the AV nucleus did not yield a significant effect of the group factor. However, a separate analysis of the data of rabbits that did learn demonstrated significant discriminative AV thalamic plasticity, whereas significant plasticity was not found in a separate analysis of the AV thalamic data of rabbits that did not learn.

\section{Neuronal activity before training}

Inspection of Figure 4 suggested that the magnitude of toneelicited neuronal responses before training (during preliminary training with tones and unpaired foot shock presentation) was reduced in rabbits with lesions. However, simple effect tests comparing neuronal activity during preliminary training in rabbits with lesions with that of controls did not reveal significant differences. Additional analyses restricted to the preliminary training data alone did reveal that the activity from 10 to $200 \mathrm{msec}$ after CS onset in the MD nucleus was reduced during preliminary training in rabbits with lesions compared with controls $(P<0.05)$. A similar reduction of the activity in the MD nucleus was found during the preliminary training session in which only the tones were presented with no foot shock. Thus, in addition to the prevention of plasticity development, the amygdalar lesions were associated with a reduction of MD thalamic tone-elicited neuronal activity before training. This reduction of elicited activity during preliminary training was not found in the anterior cingulate cortex or the AV thalamic nucleus.

\section{DISCUSSION}

Lesions of the amygdala in rabbits blocked the acquisition of discriminative active avoidance behavior, indicating that the integrity of the amygdala is a requirement of this acquisition. Past studies have demonstrated the development during acquisition of excitatory and discriminative training-induced neuronal plasticity in several cingulothalamic areas (for review, see Gabriel, 1993). Excitatory plasticity is an increase in neuronal firing elicited by the $\mathrm{CS}+$ during training relative to discharges elicited before training when CS and unpaired reinforcer presentations are given. Discriminative plasticity is the development of greater neuronal discharges in response to the $\mathrm{CS}+$ than to the $\mathrm{CS}-$. The present study showed that the amygdalar lesions abolished the development of both excitatory and discriminative plasticity, indicating that the integrity of the amygdala is necessary for both forms of plasticity.

The interpretation of studies such as this one, which use the electrolytic technique for lesion induction, must consider the possibility that damage to passing fibers or to areas adjacent to the target area contributed to the effects of the lesions. The following considerations render these possibilities unlikely for the present results. A strong correlation was observed between the severity of the behavioral deficit and the amount of damage in particular amygdalar nuclei. In addition, temporary inactivation of amygdalar neurons with microinjection of the GABA agonist muscimol, which does not affect neurotransmission in passing fibers, also blocked cingulothalamic plasticity and acquisition of discriminative avoidance behavior (Poremba and Gabriel, 1995). Finally, lesions of the medial geniculate (MG) nucleus which blocked amygdalar plasticity also eliminated cingulothalamic plasticity as found after direct amygdalar lesions in the present study. Just as amygdalar neurons, neurons of the medial geniculate (MG) nucleus of the thalamus exhibited training-induced discriminative neuronal plasticity during discriminative avoidance learning (Gabriel et al., 1975, 1990). The MG nucleus, the auditory relay for audition, supplies afferents to the amygdala and to periamygdalar areas (LeDoux et al., 1988), and bilateral lesions of the MG nucleus abolished learning as well as basolateral amygdalar and cingulothalamic discriminative plasticity (Poremba and Gabriel, 1993). The effect of the MG nuclear lesions was not attributable to a direct projection of $\mathrm{MG}$ neurons to the limbic thalamus, because such a projection does not exist (Sikes and Vogt, 1987; Poremba et al., 1994;).

The hypothesis that fostered this study stated that amygdalar lesions will attenuate specifically anterior cingulate cortical and MD thalamic training-induced plasticity. This hypothesis was based on the fact that plasticity develops in parallel in the early training stages in all of these areas, and there are direct axonal projections from the amygdala to the anterior cingulate cortex and MD nucleus (see the introductory remarks). We thus did not expect the amygdala lesions to block the discriminative plasticity of the AV thalamic nucleus. Amygdalar neurons do not project directly to the anterior thalamus, and unlike amygdalar discriminative plasticity, AV thalamic plasticity does not develop until the 


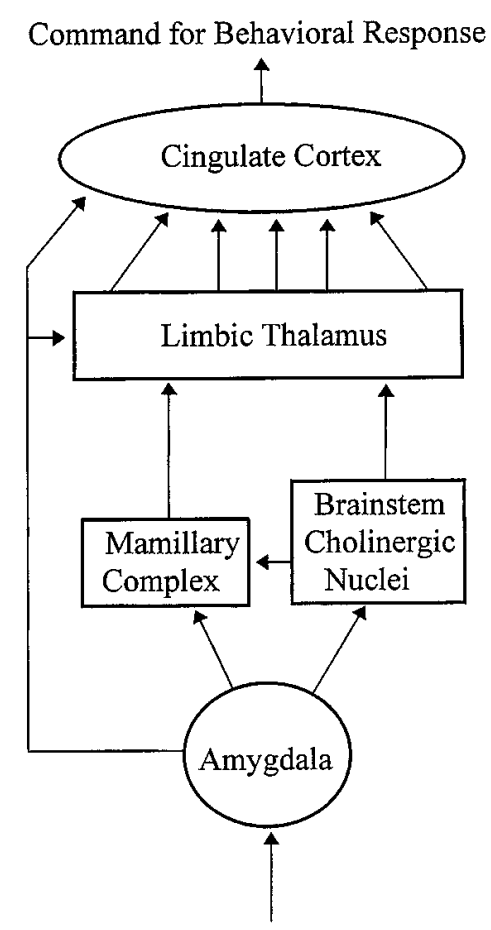

CS \& US Information

Figure 5. Schematic depiction of the brain structures that mediate the processes necessary for discriminative avoidance learning. Amygdalar efferents depicted by the arrow on the left are involved in establishment of early developing cingulothalamic discriminative plasticity. Amygdala efferents depicted by the obliquely angled arrows are involved in establishment of late-developing cingulothalamic discriminative plasticity. US, Unconditioned stimulus.

late training stage, when asymptotic levels of behavioral discrimination are first attained. Nevertheless, the data indicate that the integrity of the amygdala is essential for establishment of the late-developing AV thalamic discriminative plasticity. This result raises the question, by what route do amygdalar efferents influence the development of late cingulothalamic discriminative plasticity?

It is possible that amygdalar projections to the mamillary hypothalamic nuclei are involved. Amygdalar neurons send axons to the vicinity of the mamillary nuclei directly (Hopkins and Holstege, 1978; Krettek and Price, 1978; Price and Amaral, 1981; Caffé et al., 1987; Canteras et al., 1992) and via a synapse in the bed nucleus of the stria terminalis (Price et al., 1987; Swanson, 1987). Neurons of the mamillary nuclei provide strong input to the limbic thalamus (Seki and Zyo, 1984; Hayakawa and Zyo, 1989; Shibata, 1992). Neuronal recordings in the lateral mamillary nuclei, the supramamillary nuclei, and the medial mamillary nuclei exhibited late-developing discriminative plasticity (Kubota et al., 1994). Lesions of the mamillothalamic tract abolished AV thalamic excitatory and discriminative plasticity, and these lesions impaired discriminative avoidance performance in the late stages of acquisition (Gabriel et al., 1995). Amygdalar neurons also send axons to the brainstem cholinergic lateral dorsal tegmental and pedunculopontine nuclei (Hopkins and Holstege, 1978). Lesions of these nuclei also disrupted asymptotic performance of the avoidance behavior (Kubota et al., 1993), and these nuclei project acetylcholine-containing axons to mamillary and limbic tha- lamic nuclei, raising the possibility that amygdalar efferents may influence the cingulothalamic areas via the amygdalotegmental projection. The suggested flows of neuronal activity from the amygdala (Fig. 5) could induce the changes that bring about observed late development of discriminative plasticity in the mamillary and supramamillary nuclei (Kubota et al., 1994). The late mamillary discriminative activity may be relayed directly from these areas to the limbic (anterior and MD) thalamic nuclei, from the limbic nuclei to the cingulate cortex, and onward to the striatum to induce the output of the behavioral response. Direct information flow from the amygdala to the anterior cingulate cortex and to the MD thalamic nucleus may account for the occurrence of early discriminative plasticity in these areas.

Our current working hypothesis concerning the functional significance of the discriminative activity is presented in other reports (e.g., Gabriel, 1990, 1993). Briefly, it is proposed that particular task-, and training stage-specific topographic distributions of brief latency $\mathrm{CS}+$ elicited cingulothalamic neuronal activity give rise to premotor "command volleys" in the cingulate cortex (Kubota et al., 1996), which are projected to striatal areas to trigger the output of the primed avoidance response.

The present results are compatible with past theoretical accounts, which view active avoidance learning as a product of two processes, acquisition of an emotional response of "fear" to the conditional stimulus and instrumental learning of the skeletomotor avoidance response (Miller and Konorski, 1928; Pavlov, 1932; Skinner, 1938; Mowrer, 1947; Spence, 1956; Rescorla and Solomon, 1967; Trapold and Overmier, 1972). The present data are also in accord with other results in indicating a major role of the amygdala in fear conditioning (LeDoux, 1990; Davis, 1992; Kapp et al., 1992; Kesner et al., 1992; Fanselow et al., 1994). In addition, it is shown here that amygdala neurons are involved in the acquisition of the instrumental response, centered in the limbic thalamus and cingulate cortex. These findings may also account for the recent findings suggesting that the role of the amygdala is time-limited, i.e., necessary for the acquisition but not the maintenance of some types of associative learning (Brady et al., 1954; Thatcher and Kimble, 1966; Aigner et al., 1991; Parent et al., 1992, 1995; Roozendaal et al., 1993; Burns et al., 1994). The amygdala is necessary for initiating the training-induced changes in the limbic thalamus, but once initiated, the amygdalar involvement is reduced. This process is accelerated by virtue of the fact that the instrumental response enables the subject to gain control over the aversive stimulus that was originally the source of fear.

\section{REFERENCES}

Aigner TG, Walker DL, Mishkin M (1991) Comparison of the effects of scopolamine administered before and after acquisition in a test of visual recognition memory in monkeys. Behav Neural Biol [erratum (1991) 55:380] 55:61-67.

Applegate CD, Frysinger RC, Kapp BS, Gallagher M (1982) Multiple unit activity recorded from amygdala central nucleus during Pavlovian heart rate conditioning in rabbit. Brain Res 234:251-262.

Blanchard DC, Blanchard RJ (1972) Innate and conditioned reactions to threat in rats with amygdalar lesions. J Comp Physiol Psychol 81:281-290.

Brady JV, Schreiner L, Geller I, Kling A (1954) Subcortical mechanisms in emotional behavior: the effect of rhinencephalic injury upon the acquisition and retention of a conditioned avoidance response in cats. J Comp Physiol Psychol 47:179-186. 
Brogden WJ, Culler FA (1936) A device for motor conditioning of small animals. Science 83:269.

Burns LH, Everitt BJ, Robbins TW (1994) Intra-amygdala infusion of the $N$-methyl-D-aspartate receptor antagonist AP5 impairs acquisition but not performance of discriminated approach to an appetitive CS. Behav Neural Biol 61:242-250.

Caffé AR, van Leeuwen FW, Luiten PGM (1987) Vasopressin cells in the medial amygdala of the rat project to the lateral septum and ventral hippocampus. J Comp Neurol 261:237-252.

Cahill L, McGaugh JL (1990) Amygdalar complex lesions differentially affect retention of tasks using appetitive and aversive reinforcement. Behav Neurosci 104:532-543.

Carew TJ, Hawkins RD, Abrams TW, Kandel ER (1984) A test of Hebb's postulate at identified synapses which mediate classical conditioning in Aplysia. J Neurosci 4:1217-1224.

Canteras NS, Simerly RB, Swanson LW (1992) Connections of the posterior nucleus of the amygdala. J Comp Neurol 324:143-179.

Davis M (1992) The role of the amygdala in conditioned fear. In: The amygdala: neurobiological aspects of emotion, memory, mental dysfunction (Aggelton JP, ed), pp 255-305. New York: Wiley-Liss.

Fanselow MS, Kim JJ, Yipp J, De Oca B (1994) Differential effects of the $\mathrm{N}$-methyl-D-aspartate antagonist DL-2-amino-5-phosphonovalerate on acquisition of fear of auditory and contextual cues. Behav Neurosci 108:235-240.

Gabriel M (1990) Functions of anterior and posterior cingulate cortex during avoidance learning in rabbits. In: Progress in brain research, Vol 85 (Uylings HBM, Van Eden CG, De Bruin JPC, Corner MA, Feenstra MGP, eds), pp 467-483. Amsterdam: Elsevier.

Gabriel M (1993) Discriminative avoidance learning: a model system. In: Neurobiology of cingulate cortex and limbic thalamus: a comprehensive handbook (Vogt BA, Gabriel M, eds), pp 478-523. Boston: Birkhauser.

Gabriel M, Saltwick SE, Miller J (1975) Conditioning and reversal of short-latency multiple-unit responses in the rabbit medial geniculate nucleus. Science 189:1108-1109.

Gabriel M, Sparenborg S, Stolar N (1987) Hippocampal control of cingulate cortical and anterior thalamic information processing during learning. Exp Brain Res 67:131-152.

Gabriel M, Cox A, Perrine C (1990) Brainstem substrates of conditioning and learning. In: Brainstem mechanisms of behavior (Vertes RP, Klemm WR, eds), pp 269-313. New York: Wiley.

Gabriel M, Kubota Y, Sparenborg S, Straube K, Vogt BA (1991) Effects of cingulate cortical lesions on avoidance learning and training-induced unit activity in rabbits. Exp Brain Res 86:585-600.

Gabriel M, Cuppernell C, Shenker JI, Kubota Y, Henzi V, Swanson D (1995) Mamillothalmic tract transection blocks anterior thalamic training-induced neuronal plasticity and impairs discriminative avoidance behavior in rabbits. J Neurosci 15:1437-1445.

Gentile CG, Jarrell TW, Teich A, McCabe PM, Schneiderman N (1986) The role of amygdalar central nucleus in the retention of differential Pavlovian conditioning of bradycardia in rabbits. Behav Brain Res 20:263-273.

Girgis M, Shih-Chang W (1981) A new stereotaxic atlas of the rabbit brain. St. Louis: Warren H. Green.

Hayakawa T, Zyo K (1989) Retrograde double-labeling study of the mamillothalamic and the mamillotegmental projections in the rat. J Comp Neurol 84:1-11.

Helmstetter FJ (1992) Contribution of the amygdala to learning and performance of conditional fear. Physiol Behav 51:1271-1276.

Hitchcock JM, Davis M (1987) Fear-potentiated startle using an auditory conditioned stimulus: effect of lesions of the amygdala. Physiol Behav 39:403-408.

Hopkins DA, Holstege G (1978) Amygdalar projections to the mesencephalon, pons and medulla oblongata in the cat. Exp Brain Res 32:529-547.

Huynh H, Feldt LS (1976) Estimation of the Box correction for degrees of freedom from sample data in randomized block and split-plot designs. J Educ Stat 1:69-82.

Kapp BS, Whalen PJ, Supple WF, Pascoe JP (1992) Amygdalar contributions to conditioned arousal and sensory information processing. In: The amygdala: neurobiological aspects of emotion, memory, and mental dysfunction (Aggelton JP, ed), pp 229-254. New York: Wiley-Liss.

Kesner RP, Berman RF, Tardif R (1992) Place and taste aversion learn- ing: role of basal forebrain, parietal cortex, and amygdala. Brain Res Bull 29:345-353.

Krettek JE, Price JL (1978) Amygdalar projections to subcortical structures within the basal forebrain and brainstem in the rat and cat. J Comp Neurol 178:225-254.

Kubota Y, Mayo J, Gabriel M (1993) Brainstem cholinergic projections and limbic thalamic training-related neuronal activity during avoidance learning in rabbits. Soc Neurosci Abstr 19:802.

Kubota Y, Burkybile C, Gabriel M (1994) Training-related neuronal activity in the mamillary complex and brainstem cholinergic nuclei during avoidance learning in rabbits. Soc Neurosci Abstr 20:797.

Kubota Y, Wolske M, Poremba A, Kang E, Gabriel M (1996) Stimulusrelated and movement-related single-unit activity in rabbit cingulate cortex and limb thalamus during performance of discriminative avoidance behavior. Brain Res 721:22-38.

LeDoux JE (1990) Information flow from sensation to emotion: plasticity in the neural computation of stimulus value. In: Learning and computational neuroscience: foundations of adaptive networks (Gabriel M, Moore J, eds), pp 3-51. Cambridge, MA: Bradford.

LeDoux JE, Iwata J, Cicchetti P, Reis DJ (1988) Different projections of the central amygdalar nucleus mediate autonomic and behavioral correlates of conditioned fear. J Neurosci 8:2517-2529.

Maren S, Poremba A, Gabriel M (1991) Basolateral amygdalar multiunit neuronal correlates of discriminative avoidance learning in rabbits. Brain Res 549:311-316.

Miller S, Konorski J (1928) Sur une forme particuliere des reflexes conditionnels. C R Seanc Soc Biol 99:1155-1157.

Mowrer OH (1947) On the dual nature of learning—a reinterpretation of "conditioning" and "problem-solving." Harvard Educ Rec $17: 102-148$.

Nishijo H, Ono T, Nishino H (1988) Single neuronal responses in amygdala of alert monkey during complex sensory stimulation with effective significance. J Neurosci 8:3570-3583.

Parent MB, Carlos T, McGaugh JL (1992) Increased training in an aversively motivated task attenuates the memory-impairing effects of posttraining $N$-methyl-D-aspartate-induced amygdala lesions. Behav Neurosci 106:789-797.

Parent MB, Quirarte GL, Cahill L, McGaugh JL (1995) Spared retention of inhibitory avoidance learning after posttraining amygdala lesions. Behav Neurosci 109:803-807.

Pascoe JP, Kapp BS (1985) Electrophysiological characteristics of amydaloid central nucleus neurons during Pavlovian fear conditioning in the rabbit. Behav Brain Res 16:117-133.

Pavlov IP (1932) The reply of a physiologist to psychologists. Psychol Rev 39:91-127.

Poremba A, Gabriel M (1993) Lesions of the medial geniculate nucleus impair avoidance learning, limbic thalamic and cingulate cortical training-induced neuronal activity in rabbits. Soc Neurosci Abstr 19:802.

Poremba A, Gabriel M (1995) The amygdala is necessary for the initial learning of discriminative avoidance behavior in rabbits, but not for long-term performance. Soc Neurosci Abstr 21:502.

Poremba A, Kubota Y, Gabriel M (1994) Afferent connections of the anterior thalamus in rabbits. Brain Res Bull 33:361-365.

Porrino LJ, Crane AM, Goldman-Rakic PS (1981) Direct and indirect pathways from the amygdala to the frontal lobe in rhesus monkey. J Comp Neurol 198:121-136.

Price JL, Amaral DG (1981) An autoradiographic study of the projections of the central nucleus of the monkey amygdala. J Neurosci 1:1242-1259.

Price JL, Russchen RT, Amaral DG (1987) The limbic region. II: the amygdalar complex. In: Handbook of chemical neuroanatomy, Vol 5: Integrated systems of the CNS, part I, hypothalamus, hippocampus, amygdala, retina (Björklund A, Hökfelt T, Swanson LW, eds), pp 279-388. Amsterdam: Elsevier.

Rescorla RA, Solomon RL (1967) Two-process learning theory: relationships between Pavlovian conditioning and instrumental learning. Psychol Rev 74:151-82.

Roozendaal B, Koolhaas JM, Bohus B (1993) The central amygdala is involved in conditioning but not in retention of active and passive shock avoidance behavior in male rats. Behav Neural Biol 59:143-149.

Seki M, Zyo K (1984) Anterior thalamic afferents from the mamillary body and the limbic cortex in the rat. J Comp Neurol 229:242-256.

Shibata H (1992) Topographical organization of subcortical projec- 
tions to the anterior thalamic nuclei in the rat. J Comp Neurol 323:117-127.

Sikes RW, Vogt BA (1987) Afferent connections of anterior thalamus in rats: sources and association with muscarinic acetylcholine receptors. J Comp Neurol 256:538-551.

Skinner BF (1938) The behavior of organisms. New York: AppletonCentury-Croft.

Spence KW (1956) Behavior theory and conditioning. New Haven, CT: Yale UP.

Spevack AA, Campbell CT, Drake L (1975) Effects of amygdalectomy on habituation and CER in rats. Physiol Behav 15:199-207.

Steinmetz JE, Thompson RF (1991) Brain substrates of aversive classical conditioning. In: Neurobiology of learning, emotion and affect (Madden IV J, ed), pp 97-120. New York: Raven.

Swanson LW (1987) The hypothalamus. In: Handbook of chemical neuroanatomy, Vol 5: Integrated systems of the CNS, part I, hypothalamus, hippocampus, amygdala, retina (Björklund A, Hökfelt T, Swanson LW, eds), pp 1-124. Amsterdam: Elsevier.

Thatcher RW, Kimble DP (1966) Effect of amygdalar lesions on retention of an avoidance response in overtrained and non-overtrained rats. Psychonomic Sci 6:9-10.

Trapold MA, Overmier JB (1972) The second learning process in instrumental learning. In: Classical conditioning II: current research and theory (Black AH, Prokasy WF, eds), pp 427-452. New York: Appleton-Century-Croft.

Willner J, Gallagher M, Graham PW, Crooks GB (1991) N-Methyl-Daspartate antagonist D-APV selectively disrupts taste-potentiated odor aversion learning. Behav Neurosci 106:315-232.

Winer BJ (1962) Statistical principles in experimental design. New York: McGraw-Hill. 